\title{
Modification of exhaled air nitric oxide in patients with asthma - cortisone monotherapy or dual inhalation therapy?
}

\author{
Victoria Maria Ruta ${ }^{1, A, D, F \oplus}$, Nicoleta Stefania Motoc ${ }^{2, B, F}$, Doina Adina Todea ${ }^{2, E \oplus}$, \\ Teodora Gabriela Alexescu ${ }^{3, D \oplus}$, Dan Valean ${ }^{4, C \oplus}$, Stefania Cozac ${ }^{4, C} \odot$, Sorina Cezara Coste ${ }^{3, D} \odot$, \\ Razvan Andrei Codea ${ }^{5, \mathrm{~B} \oplus}$, Rodica Ana Ungur ${ }^{6, \mathrm{D}-\mathrm{E} \oplus}$, Carmen Monica Pop ${ }^{2, \mathrm{E}-\mathrm{F} \oplus}$, Adina Man Milena ${ }^{2, \mathrm{D} \odot}$ \\ 1 'Iuliu Hatieganu' University of Medicine and Pharmacy, Cluj-Napoca, Romania \\ 2 Department of Pneumology, 'Iuliu Hatieganu' University of Medicine and Pharmacy, Cluj-Napoca, Romania \\ ${ }^{3}$ Department of Internal Medicine, ,Iuliu Hatieganu' University of Medicine and Pharmacy, Cluj-Napoca, Romania \\ ${ }^{4}$ MD student, Iuliu Hatieganu' University of Medicine and Pharmacy, Cluj-Napoca, Romania \\ ${ }^{5}$ Faculty of Veterinary Medicine, University of Agricultural Science and Veterinary Medicine, Cluj-Napoca, Romania \\ ${ }^{6}$ Department of Rehabilitation, 'Iuliu Hatieganu' University of Medicine and Pharmacy Cluj-Napoca, Cluj-Napoca, \\ Romania \\ A - Research concept and design, B - Collection and/or assembly of data, C - Data analysis and interpretation, \\ $D$ - Writing the article, $E$ - Critical revision of the article, $F$ - Final approval of article
}

Ruta VM, Motoc NS, Todea DA, Alexescu TG, Valean D, Cozac S, Coste SC, Codea RA, Ungur RA, Pop CM, Milena AM. Modification of exhaled air nitric oxide in patients with asthma: cortisone monotherapy or dual inhalation therapy? Ann Agric Environ Med. 2021 ; 89-93: 89-93. doi: $10.26444 / a a e m / 130712$

\begin{abstract}
Introduction. Asthma, a chronic lung disease, is a major health challenge worldwide with increased addressability to health services. There are different asthma phenotypes, which have different evolution and can be specifically tracked. The measurement of fractional expired nitric oxide (FeNo) with different devices reflects the eosinophilic inflammation of the airways, and can be used to evaluate the allergic phenotype and predict the treatment responses. The new GINA (Global Initiative for Asthma) guideline recommends FeNO monitoring to assess adherence to cortisone treatment in high doses before prescribing biological treatment, and as a means of monitoring the decrease in oral corticosteroid treatment.

Objective. The aim of the study is to analyze the applicability of FeNO in monitoring response to therapy.

Materials and method. An observational study was carried out on 129 subjects with a previously established diagnosis of asthma. The research was based on the determination of FeNO with NObreath. Those with intermediate FeNO received a low dose of inhaled corticosteroids in mono/dual therapy, those with increased FeNO received medium ICS mono/dual therapy. FeNO testing, its values and doses of ICS were below the the ATS / ERS guidelines.

Results. FeNO reduction is strictly dependent on the cortisone dose. Applying the dual therapy from the beginning does not bring additional benefits in comparison with cortisone in monotherapy, in terms of FeNO value.

Conclusion. Recommendations that include FeNO testing can help monitor response to treatment.
\end{abstract}

\section{Key words}

asthma, dual therapy, fractional expired nitric oxide (FeNO), inhalation monotherapy, wheezing

\section{INTRODUCTION}

Asthma is a major health challenge worldwide, affecting more than 300 million people and $10 \%$ of all Europeans [1]. The number of exacerbations has also increased dramatically, exceeding 500,000 hospitalizations every year [2]. Epidemiological studies claim that by 2020 , chronic lung diseases will become the fourth leading cause of death in the world [3]. Clinically, asthma is characterized by wheezing, coughing, dyspnea and chest constriction [1]. Under adequate drug control, patients are asymptomatic and the quality of life is not affected. There are situations in which patients tolerate the symptoms very well, attribute them to age, occupational exposure or other factors, the context in which we do not have an objective assessment of asthma. Unfortunately,

Address for correspondence: Rodica Ana Ungur, Department of Rehabilitation, Iuliu Hatieganu' University of Medicine and Pharmacy Cluj-Napoca, 46-50 Viilor Street, 400347, Cluj-Napoca, Romania.

E-mail: rodica.ana.ungur@gmail.com

Received: 21.09.2020; accepted: 20.11.2020; first published:08.12.2020 these patients limit their daily activity and should be made aware that a sedentary lifestyle exposes them to the risk of aggravating symptoms, and they should be encouraged to practice sport at the limit of self-tolerance [4].

Environmental factors are a major problem in daily life in terms of quality of life and long-term evolution [5]. Mechanical and chemical stress are considered to be factors which induce the growth of free radical production and, as a consequence, tissue oxidative destruction occurs [6]. Tissue oxidative stress assessment has become the target of research on different organs. The importance of oxidative stress in osteoarthritis disease is fully recognized at present [7]. In cardiovascular pathology, the increase of oxidative stress promotes atherosclerosis with related complications (hypertension, dyslipidaemia, peripheral artery disease, metabolic syndrome, diabetes and obesity) $[8,9]$. Starting from this premise, in recent years, we have resorted to the evaluation of the fraction of exhaled nitric oxide (FeNO) as an objective marker of eosinophilic bronchial inflammation. 
From a pathophysiological point of view, asthmatic patients have an increased expression of inducible nitric oxide synthase (iNOS) in the airway epithelial cells, and an increased level of nitric oxide (NO) in the expired air $[10,11]$. FeNO is a measure of airway inflammation assessment and oxidative stress, as mentioned above [12]. Also, the level of FeNO is well correlated with the presence and level of inflammation and decreases with glucocorticoid treatment [13].

The new GINA (Global Initiative for Asthma) guideline recommends measuring FeNO as an assessment tool for treating patients with difficult asthma. FeNO monitoring is indicated to assess adherence to cortisone treatment in high doses before prescribing biological treatment. The guide also recommends measuring FeNO as a means of monitoring the decrease in oral corticosteroid treatment [14].

The current study analysed the applicability of FeNO assessment in monitoring the response to therapy, evaluating current symptom control and predicting asthma exacerbations.

\section{MATERIALS AND METHOD}

An analytical and observational study was carried out on 129 subjects, all over 18 years of age, with a previously established diagnosis of asthma, with different persistent respiratory symptoms for at least 7 days.

All procedures performed in the study involving human participants were in accordance with the ethical standards of the institutional and national research committee and with the 1964 Helsinki Declaration and its latter amendments or comparable ethical standards. The study was granted ethics' approval by the Ethics Committee of the 'Hospital of Rehabilitation Eurotrat' Gherla, Cluj county, Romania, in January 2018. Informed consent was obtained from each individual participating in the study. The study was carried out on all subjects between February - July 2018.

Inclusion criteria:

1) a diagnosis of asthma of at least 1 year;

2) the presence of respiratory symptoms in the past 7 days;

3) skin allergic tests, for evaluation of the atopic field, within the past year;

4) a pulmonary x-ray in the past year (a high prevalence of tuberculosis infection in Romania is well-known);

\section{Exclusion criteria:}

1) association with COPD (Chronic Obstructive Pulmonary Disease), Overlap syndrome;

2) continuous exposure to respiratory allergens (bakers, hairdressers, industrial toxic environment, etc.).

Smoking was not a reason for exclusion.

Study protocol: After inclusion/exclusion criteria, all patients were assessed at the time of presentation, during visit 1 (V1), after 3 months, during visit 2 (V2) and after 6 months, and on their last evaluation, during visit 3 (V3). All visits were in the morning, at approximately the same time, following the ATS (American Thoracic Society) test criteria for NO in expired air and the ATS spirometry guide. FeNO was measured twice, and a third measurement was required if there was more than $10 \%$ difference between the first 2 measurements [15].

FeNO decreased at the end of exercise in both normal and asthmatic subjects [16]. Therefore, to avoid errors, the patients rested for 30 minutes before testing. FeNO testing was the first manoeuvre performed, using the NObreath ${ }^{\oplus}$ device (breath NO test system intended to measure FeNO in parts per billion (ppb) in exhaled breath) [17].

The subject breathed room air with a temperature between $22-25^{\circ} \mathrm{C}$. Interpretation of the values was carried out following the ATS 'Interpretation of FeNO for Clinical Applications':

- Intermediate NO: between 25ppb - 50ppb;

- High level NO: over 50 ppb [14].

These cut-offs have been described for adult non-smoking subjects. It is well acknowledged that smoking reduces FeNO in both healthy and asthmatic subjects [18], and the magnitude of the reduction seems to depend on the daily cigarette consumption [19]. The magnitude of smoking can be assessed by carbon monoxide concentration in exhaled air which represents a sure proof of recent smoking [20], thus being able to correlate it with the reality of the FeNO value. Tobacco use is detrimental to health and all health professionals have the duty to intervene and initiate tobacco cessation. Prevention programmes should focus on the medical education of both children and parents [21].

Exposure to chemical substances can induce an exaggerated immune response in susceptible individuals. Farmers, printers, painters, cleaners, and wood/plastic/ electrical/ health care workers are considered as being at high-risk exposure [22]. These categories of patients are at risk for occupational asthma, with intensely increased, persistent FeNo values due to exposure to allergens. FeNO test at 2-48 hours after exposure to allergens is at a maximum [23].

\section{VISIT METHODOLOGY}

V1 - first visit. The patient filled-in the ACQ (Asthma Control Questionnaire) to assess symptoms in the past 7 days. The ACQ has strong measurement properties and has been fully validated for use in both clinical practice and clinical trials, starting with 1998 -1999 by both ATS / ERS companies.

NO in the exhaled air was tested.

The last measurement was spirometry, according to ATS / ERS criteria, performed with the Spirobank II Basic spirometer.

Because asthma is a highly variable disease, symptoms might fluctuate substantially from day-to-day [24], and for that reason, the pretesting ACQ questionnaire was used to not evaluate FeNO in a patient with asthma exacerbation.

V2 - the second visit, after 3 months. The patient's FeNO was tested.

V3 - the third visit, after 6 months. The patient's FeNO was tested.

Depending on the FeNO value, intermediate and high level, the subjects were divided into 2 randomized groups of cortisone inhaler (ICS) therapy: ICS in monotherapy or dual therapy (ICS and Long-Acting Beta Agonist (LABA) combination). At the base of the randomization stood the dose of cortisone, small or medium category, according to GINA ICS low, medium and high doses [25]. 
1) Subjects with intermediate FeNO, 25ppb-50ppb, had an indication of inhalation treatment with low dose ICS, (mono/dual dose).

2) Subjects with high FeNO, over $50 \mathrm{ppb}$, had an indication of inhalation treatment with a medium dose of ICS (mono/ dual dose).

3) There was no randomization on high doses of cortisone.

Statistical analysis. Database processing was performed in Excel and interpretation by IBM SPSS v20.0. The tests used were the T-test for independent samples and the Chi-Squared test. Differences were considered significant when $\mathrm{p}<0.05$.

\section{RESULTS}

Patients presenting with worsening of the general condition during V2 were excluded from the study for further investigation. In 2 patients, the general condition worsens until the next visit, requiring further evaluation and the combination of new drugs for the undiagnosed comorbidities during V1, while one patient voluntarily withdrew.

Demographic data of subjects. The age distributions, body weights and heights did not differ significantly between the 2 groups. There was a significant correlation between the presence of atopic terrain and the $\mathrm{NO}$ value in the exhaled air [1] (Tab. 1; Fig. 1).

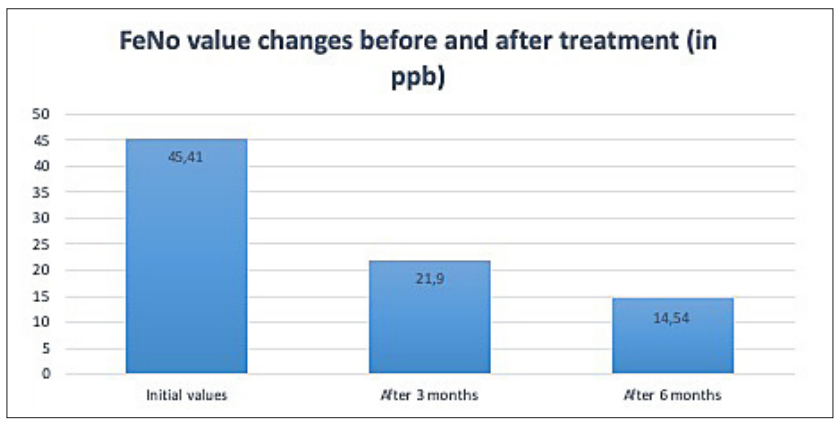

Figure 1. Value of FeNO depending of the presence of atopy ground

Table 1. The value of FeNO depending on the presence of atopy ground

\begin{tabular}{lc}
\hline Without atopy & 33.14 \\
\hline With atopy & 61.25 \\
\hline p value & 0.02 \\
\hline
\end{tabular}

FeNO value and presence of symptoms. Of all the symptoms present at the beginning, an association was observed between wheezing and a high FeNO value (Fig. 2). This association has been reported in children in other studies.

Elevated FeNO levels as a risk factor for persistent wheezing. FeNO measurement may serve as an additional parameter for predicting persistent wheezing in preschool children [26]. No association was found between other specific symptoms and $\mathrm{FeNO}$ values.

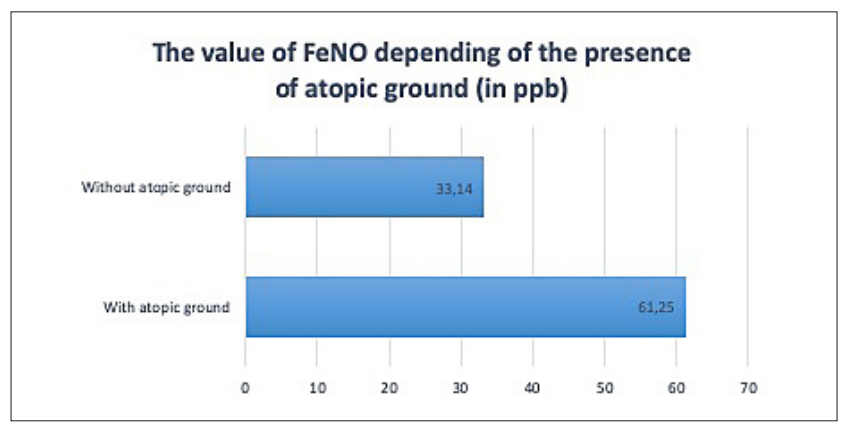

Figure 2. Vlue of FeNO in relationship with wheezing

\section{CHANGES IN FENO LEVELS AFTER TREATMENT}

Modification of FeNO after therapy start. To compare the differences in NO values in the sample, the ANOVA test was used for means comparison. The average value of the initial NO was $45.41 \mathrm{ppb}(+-33.00$ standard deviation), while the average value of the NO after 3 months was $21.90 \mathrm{ppb}(+-$ 24.51 st. dev.) and $14.54 \mathrm{ppb}$ (+- 12.42 st. dev.), respectively, $\mathrm{fter} 6$ months. Following the test, this difference is statistically significant $(\mathrm{p}=0.0001)$ with a significant reduction of FeNO values in both groups of patients (Fig. 3).

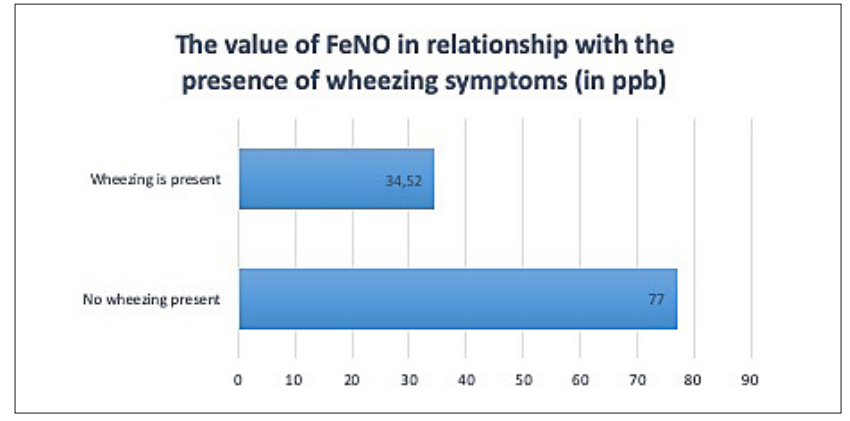

Figure 3. FeNo changes during treatment

Modification of FeNO depending on the cortisone dose - small/medium. Regarding the therapeutic arms and the FeNO modification under different doses and inhalation medications, FeNO modification was initially evaluated according to the cortisone dose (Fig. 4).

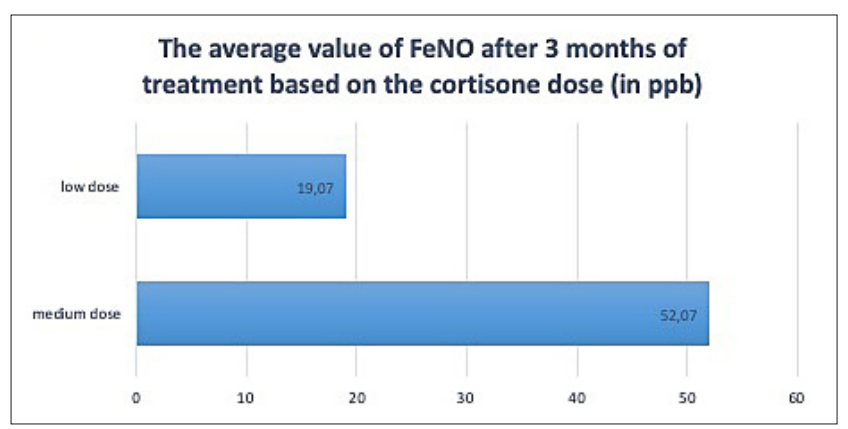

Figure 4. Average difference of FeNO at 3 months of treatment depending on the cortisone dose

To highlight the existence of a link between the value of FeNO after 3 months of treatment and the dose of cortisone, the T-test for independent sample was used. The difference after 3 months for patients treated with a low dose of cortisone 
was $19.07 \mathrm{ppb}(+-13.39 \mathrm{st}$. dev.), whereas in patients treated with a medium dose of cortisone itwais $52.07 \mathrm{ppb}(+-35.19$ st. dev.).

Using the T-test for independent samples, it was concluded that this difference was statistically significant $(\mathrm{p}=0.005)$, the average dose of cortisone being significantly higher than the small dose, with a much faster reduction of FeNO values.

Modification of FeNO according to the randomization arm. In monotherapy, there was an average decrease of 33.34 $\mathrm{ppb}$, while in dual therapy there was an average decrease of $28.19 \mathrm{ppb}$. This difference was not statistically significant (Fig. 5).

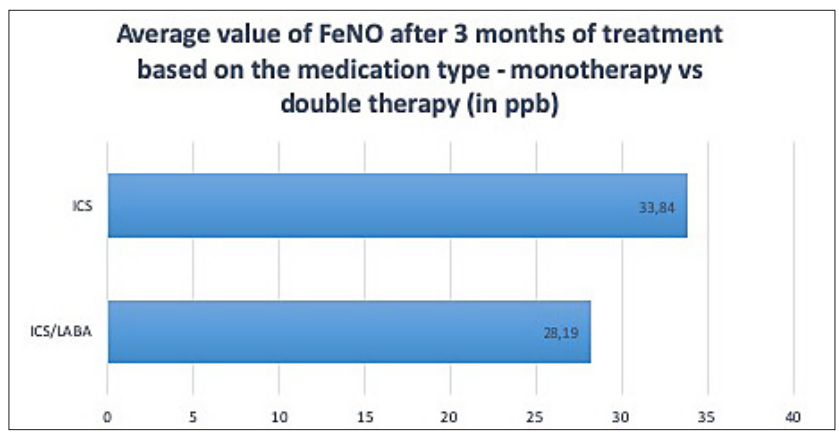

Figure 5. Mean difference of FeNO at 3 months of treatment depending on medication.

\section{DISCUSSION}

High FeNO is evidence of uncontrolled inflammation and is associated with increased risk for asthma exacerbations and potential future deterioration, even when there is a lack of corroborating symptoms or normal lung function [27].

Numerous studies on other pathologies proved that inflammation markers were significantly correlated with muscle strength, walking distance and cognitive impairment [28]. Therefore, in the present study, the FeNO measurement was performed after excluding the previously listed factors, and after a 30 -minute seated rest period.

The use of ICS is proven to be effective in treating asthma [29]. ICS can reduce asthma symptoms and inhibit the activity of inflammatory cells, including eosinophils, T lymphocytes, mast cells, macrophages, dendritic cells and neutrophils [30]. These remarkable effects of corticosteroids are produced by suppressing the production of chemotactic mediators, adhesion molecules and inhibiting the survival of these inflammatory cells in the airways [31].

Starting from specialized literature data, the aim of the current study was to follow the modification of $\mathrm{NO}$ in asthmatic subjects according to the administration of ICS in monotherapy, compared to dual therapy and depending on the used doses of cortisone.

Both groups on ICS mono/dual therapy showed FeNO enhancement, after 3 and 6 months. In conclusion, the FeNO value is not influenced by mono / dual therapy.

In conclusion, the administration of ICS is mandatory. Twenty-two studies demonstrated that FeNO levels declined after the administration of ICS. The response was seen after 4 -8 weeks of treatment, although one study showed reduction after 10 days, without further reduction observed at 40 days [32]. In the current study, there was a significant reduction of FeNO after 3 months, regardless of the therapeutic arm.

During the 3-month evaluation, a lower FeNO was observed in patients with an average dose of cortisone, compared with patients with a low dose, regardoless of monotherapy or dual therapy; therefore, the decline in FeNO is ICS dosedependent.

In patients with uncontrolled asthma treated with ICS, the guides recommend increasing the dose of ICS or adding a LABA to the low doses of ICS [33]. There are studies which suggest that adding a LABA to ICS may be more beneficial in controlling asthma than increasing the dose of corticosteroids alone [34].

Regarding the primary intention administration, dual or monotherapy, this study did not find superior efficacy of dual therapy in reducing FeNO, with monitoring after 3 and 6 months. In this context, and the current guidelines for asthma, the ICS/LABA treatment is recommended when asthma is not well controlled by low maintenance ICS plus Short-Acting Beta Agonist (SABA) treatment. These recommendations are not based on efficacy, but the higher cost of combination drugs $[35,36]$. However, the combination of ICS in low doses with rapid onset LABA is effective for reducing symptomatology and increasing the quality of life.

FeNO levels decrease rapidly after initiation of ICS therapy, whether dual monotherapy, as shown in the presented study, while literature confirms that FeNo level increases very rapidly after discontinuation of corticosteroid therapy [37]. The dynamic follow-up of FeNO level helps to assess whether the asthma is under control, and guide ICS treatment in asthmatic patients.

The ATS clinical guidelines suggest that FeNO over 50 $\mathrm{ppb}$ indicate the need for stepping-up treatment, but no clear recommendations exist for lower FeNO levels [38].

There are studies which claim that FeNO is the most sensitive inflammatory marker for evaluating the antiinflammatory effects of ICS on asthmatic patients. However, the reduction of FeNO after ICS treatment may not ensure optimal suppression of airway inflammation [39], and may not be able to require increasing / decreasing of ICS doses solely on its value [40]. Further studies are required for a more difinitive evaluation.

\section{CONCLUSIONS}

Although it was not within the scope of this study, the association was observed between wheezing and increased FeNO in patients with atopic terrain, which is consistent with data underlined by literature, numerous publications highlighting much higher FeNO values and the presence of atopic terrain, proven by positive skin tests or bronchial challenge tests [32].

Unfortunately, the evaluation of FeNO is not a sensitive or specific marker. It can be indicated for the evaluation of asthma, but does not enter the standard protocol.

Study limitations. Limitation of the study were the small number of subjects included, and that the patients could not be monitored for a longer period to evaluate FeNo at the therapy step-down, because they were not locals and access to rural areas was difficult. There was no control group and absolute FeNO values varied depending on the device used. 


\section{Acknowledgments}

The first two authors have equal rights to this paper.

\section{REFERENCES}

1. Global Strategy for Asthma Management and Prevention (2018 update) https://ginasthma.org/wp-content/uploads/2018/04/wms-GINA-2018report-tracked_v1.3.pdf (access:2020.09.08)

2. Masefield S, Edwards J, Hansen K, Hamerlijnck D, Lisspers K, Schee $\mathrm{M}$ van der, et al. The future of asthma research and development: a roadmap from the European Asthma Research and Innovation Partnership (EARIP). Eur Respir J. 2017; 49(5).

3. Croitoru A, Bogdan MA. [Evidences related to pulmonary rehabilitation in the respiratory pathology]. Pneumol Buchar Rom. 2014 Jun; 63(2): $88-90,92-5$

4. Nistor AR, Onac I, Stefanescu A, Borda IM, Ciortea V, Ungur R. EBSCOhost | 108800415 | The role of singing therapy in pulmonary rehabilitation. Palestrica of the Third Millennium Civilization \& Sport. 2015; 16(2).

5. Georas SN, van Wijngaarden E, Rich DQ. Air pollution and asthma incidence: doubt no more? Lancet Respir Med. 2015 Dec; 3(12): 902-3.

6. Rezaei Vandchali N, Koolivand A, Ranjbar A, et al. Oxidative toxic stress and p53 level in healthy subjects occupationally exposed to outdoor air Pollution - a cross-sectional study in Iran. Ann Agric Environ Med. 2020. doi: 10.26444/aaem/126313

7. Ungur R, Dronca M, Crăciun EC, Rusu RL, Văleanu M, Onac I, et al. Improvement of total antioxidant status, a possible bioeffect of the ultrasound therapy - a pilot study. Rev Romana Med Lab. 2011; 19(2): 177-83.

8. Pignatelli P, Menichelli D, Pastori D, Violi F. Oxidative stress and cardiovascular disease: new insights. Kardiol Pol. 2018; 76(4): 713-22.

9. Cozma A, Sitar-Taut A, Orăşan O, Leucuta D, Alexescu T, Stan A, et al Determining Factors of Arterial Stiffness in Subjects with Metabolic Syndrome. Metab Syndr Relat Disord. 2018 Sep 5; 16(9): 490-6.

10. Barnes PJ, Liew FY. Nitric oxide and asthmatic inflammation. Immunol Today. 1995 Mar; 16(3): 128-30.

11. Lemière C, Ernst P, Olivenstein R, Yamauchi Y, Govindaraju K, Ludwig MS, et al. Airway inflammation assessed by invasive and noninvasive means in severe asthma: Eosinophilic and noneosinophilic phenotypes. J Allergy Clin Immunol. 2006 Nov 1; 118(5): 1033-9.

12. Matacuta I, Neamtu MB, Bodrug N, Dobrota L, Neamtu ML, Caprita H. Metode de explorare funcțională pulmonară. Rev Stiintifico-Pract Info-Med. 2013; 1(21): 32-6.

13. Hoyte FCL, Gross LM, Katial RK. Exhaled Nitric Oxide: An Update. Immunol Allergy Clin North Am. 2018; 38(4): 573-85.

14. Pocket guide for asthma management and prevention (GINA-2019) https:/ginasthma.org/wp-content/uploads/2019/04/GINA-2019-mainPocket-Guide-wms.pdf (access:2020.09.08)

15. Dweik RA, Boggs PB, Erzurum SC, Irvin CG, Leigh MW, Lundberg JO, et al. An Official ATS Clinical Practice Guideline: Interpretation of Exhaled Nitric Oxide Levels (FeNO) for Clinical Applications. Am J Respir Crit Care Med. 2011 Sep 1; 184(5): 602-15.

16. Terada A, Fujisawa T, Togashi K, Miyazaki T, Katsumata H, Atsuta $J$, et al. Exhaled Nitric Oxide Decreases during Exercise-induced Bronchoconstriction in Children with Asthma. Am J Respir Crit Care Med. 2001 Nov 15; 164(10): 1879-84.

17. NObreath manual https://www.nobreathfeno.com/wp-content/ uploads/2018/11/LAB759-NObreath-manual-Issue-4.pdf (access 2020.09.08)

18. Malinovschi A, Backer V, Harving H, Porsbjerg C. The value of exhaled nitric oxide to identify asthma in smoking patients with asthma-like symptoms. Respir Med. 2012 Jun 1; 106(6): 794-801.

19. Bjermer L, Alving K, Diamant Z, Magnussen H, Pavord I, Piacentini G, et al. Current evidence and future research needs for FeNO measurement in respiratory diseases. Respir Med. 2014 Jun 1; 108(6): 830-41.

20. Trofor A, Petris O, Trofor L, Man MA, Filipeanu D, Miron R. Biochemistry in Assessing Tobacco Exposure - Smokers versus Nonsmokers Correlations with clinical practice. Rev Chim. 2017 Jun 15; 68(5): 1002-6.
21. Trofor AC, Man MA, Marginean C, Dumitru F, Trofor L. Smoking cessation for free: outcomes of a study of three Romanian clinics. Open Med. 2016 Dec 30; 11(1): 605-10.

22. Man MA, Man SC, Motoc NŞ, Pop CM, Trofor AC. Fatal hypersensitivity pneumonitis after chemical occupational exposure. Romanian J Morphol Embryol Rev Roum Morphol Embryol. 2017; 58(2): 627-34.

23. Sastre J, Costa C, del Garcia Potro M, Aguado E, Mahillo I, FernándezNieto M. Changes in exhaled nitric oxide after inhalation challenge with occupational agents. J Investig Allergol Clin Immunol. 2013; 23(6): 421-7.

24. Rhee H, Love T, Mammen J. Comparing Asthma Control Questionnaire (ACQ) and National Asthma Education and Prevention Program (NAEPP) asthma control criteria. Ann Allergy Asthma Immunol. 2019 Jan 1; 122(1): 58-64.

25. Global Initiative for asthma https://ginasthma.org/wp-content/ uploads/2019/06/GINA-2019-main-report-June-2019-wms.pdf (access: 2020.09.08)

26. Shim JY. Association of wheezing phenotypes with fractional exhaled nitric oxide in children. Korean J Pediatr. 2014 May; 57(5): 211-6.

27. LaForce C, Brooks E, Herje N, Dorinsky P, Rickard K. Impact of exhaled nitric oxide measurements on treatment decisions in an asthma specialty clinic. Ann Allergy Asthma Immunol Off Publ Am Coll Allergy Asthma Immunol. 2014 Dec; 113(6): 619-23.

28. Tudorache E, Fildan AP, Frandes M, Dantes E, Tofolean DE. Aging and extrapulmonary effects of chronic obstructive pulmonary disease. Clin Interv Aging. 2017 Aug 16; 12: 1281-7.

29. Bateman ED, Hurd SS, Barnes PJ, Bousquet J, Drazen JM, FitzGerald JM, et al. Global strategy for asthma management and prevention: GINA executive summary. Eur Respir J. 2008; 31(1): 143-78.

30. Hauber H-P, Gotfried M, Newman K, Danda R, Servi RJ, Christodoulopoulos $\mathrm{P}$, et al. Effect of HFA-flunisolide on peripheral lung inflammation in asthma. J Allergy Clin Immunol. 2003 Jul; 112(1): 58-63.

31. Hossny E, Rosario N, Lee BW, Singh M, El-Ghoneimy D, SOH JY, et al. The use of inhaled corticosteroids in pediatric asthma: update. World Allergy Organ J https://www.ncbi.nlm.nih.gov/pmc/articles/ PMC4982274/ (access: 2020.09.08)

32. Wang Z, Pianosi P, Keogh K, Zaiem F, Alsawas M, Alahdab F, et al. The Clinical Utility of Fractional Exhaled Nitric Oxide (FeNO) in Asthma Management. Agency for Healthcare Research and Quality; https:// effectivehealthcare.ahrq.gov/topics/asthma-nitric-oxide/research/ (access: 2020.09.08)

33. Zetterström O, Buhl R, Mellem H, Perpiñá M, Hedman J, O’Neill S, et al. Improved asthma control with budesonide/formoterol in a single inhaler, compared with budesonide alone. Eur Respir J. 2001 Aug 1; 18(2): $262-8$.

34. Greening AP, Ind PW, Northfield M, Shaw G. Added salmeterol versus higher-dose corticosteroid in asthma patients with symptoms on existing inhaled corticosteroid. The Lancet. 1994 Jul 23; 344(8917): 219-24.

35. Fingleton J, Hardy J, Baggott C, Pilcher J, Corin A, Hancox RJ, et al. Description of the protocol for the PRACTICAL study: a randomised controlled trial of the efficacy and safety of ICS/LABA reliever therapy in asthma. BMJ Open Respir Res https://www.ncbi.nlm.nih.gov/pmc/ articles/PMC5647477/ (access:2020.09.08)

36. Budin CE, Maierean AD, Ianosi ES, Socaci A, Buzoianu AD, Alexescu TG, et al. Nocturnal Hypoxemia, a Key Parameter in Overlap Syndrome. Rev Chim. 2019 Mar 15; 70(2): 449-54.

37. Liu L, Urban P, Hunt JF, Wilkinson P, Laning K, Gaston B. Changes in Exhaled Nitric Oxide and Breath $\mathrm{pH}$ during Fluticasone Wean in Asthma. Respiration. 2010; 79(3): 193-9.

38. Malinovschi A, Van Muylem A, Michiels S, Michils A. FeNO as a predictor of asthma control improvement after starting inhaled steroid treatment. Nitric Oxide. 2014; 40: 110-6.

39. Jatakanon A, Uasuf C, Maziak W, Lim S, Chung KF, Barnes PJ. Neutrophilic Inflammation in Severe Persistent Asthma. Am J Respir Crit Care Med. 1999 Nov 1; 160(5): 1532-9.

40. Sl J, P H, Jo C, Em F, Rj H, Cr M, et al. Exhaled NO and assessment of anti-inflammatory effects of inhaled steroid: dose-response relationship. Eur Respir J. 2002 Sep 1; 20(3): 601-8. 